\title{
Factors responsible for poor sleep quality in patients with chronic obstructive pulmonary disease
}

\author{
Chih-Hao Chang ${ }^{1,2}$, Li-Pang Chuang ${ }^{1,2}$, Shih-Wei Lin ${ }^{1,2}$, Chung-Shu Lee ${ }^{1,2}$, Ying-Huang Tsai ${ }^{2,3}$, Yu-Feng Wei ${ }^{4}$, \\ Shih-Lung Cheng ${ }^{5,6}$, Jeng-Yuan Hsu ${ }^{7}$, Ping-Hung Kuo ${ }^{8}$, Chong-Jen $\mathrm{Yu}^{8}$ and Ning-Hung Chen ${ }^{1,2^{*}}$
}

\begin{abstract}
Background: Sleep disturbance is a common complaint in patients with chronic obstructive lung disease (COPD). However, the factors resulting in sleep disturbance remain unclear. This retrospective, observational, multicenter study aimed to identify the factors associated with sleep disturbance in patients with COPD.

Methods: The study was a retrospective, observational, and multicenter research. Data including age, sex, body mass index, smoking status, COPD inhaler prescribed, clinical symptoms, pulmonary function tests, medical history of comorbidities, and questionnaires were collected. Parameters including demographics, symptoms, medication, severity, functional classification, and comorbidities were correlated with sleep quality scores.

Results: Among 377 patients with COPD, 200 (53\%) patients experienced poor sleep quality (Pittsburg Sleep Quality Index scores > 5). A significant difference in sleep quality, as measured by PSQI scores, was noted between groups based on the 2011 Global Initiatives for Chronic Obstructive Lung Disease (GOLD) classification system. The most common sleep disturbances included "getting up to use the bathroom" (70.3 \%), "wake up at night or early morning" (40.3\%), and "cough and snore loudly at night" (15.9\%). The use of inhaled corticosteroids, the presence of wheezing, COPD Assessment Test (CAT) scores, and Modified Medical Research Council (mMRC) dyspnea scale scores positively correlated with poor sleep quality (odds ratio: 1.51, 1.66, 1.09, and 1.30, respectively). Upon multivariate analysis, the CAT score was an independent factor for poor sleep quality in these patients. With the exception of sleep problem items, based on the CAT questionnaire, phlegm was significantly higher in COPD patients with poor sleep quality.

Conclusions: Poor sleep quality is common among patients with COPD and symptoms including wheeze, phlegm, and inhaled corticosteroid use may contribute to poor sleep quality. The CAT score is a good indicator of poor sleep quality in patients with COPD.
\end{abstract}

Keywords: COPD, Pittsburgh Sleep Quality Index, COPD Assessment Test, Sleep quality

\section{Background}

Sleep disturbance is a common symptom in patients with COPD [1,2] and there are significant differences between the sleep disorders in patients with COPD and those encountered in the general population [3]. Less rapid eye movement (REM) sleep and arousals during periods of desaturation are often noted in patients with

\footnotetext{
* Correspondence: nhchen@cgmh.org.tw

'Department of Pulmonary and Critical Care Medicine, Linkou Chang-Gung Memorial Hospital, Chang-Gung medical foundation, Taoyuan, Taiwan

${ }^{2}$ Chang-Gung University College of Medicine, Taoyuan, Taiwan

Full list of author information is available at the end of the article
}

COPD [4]. Patients with COPD also become more hypoxemic during sleep than when awake and the hypoxemia during sleep is even greater than that encountered during exercise [5]. Hypoventilation is the major cause of hypoxemia during REM sleep in patients with COPD and there may be additional contributions from ventilationperfusion mismatches and reductions in functional residual capacity [6].

Recently, Nunes et al. [1] reported that $70 \%$ of patients with COPD had poor sleep quality, and the quality of sleep was the major determinant of quality of life in those patients. In the study by Scharf et al. [2] sleep quality was 
also associated with quality of life and sleep disturbance predicted poor survival in patients with COPD [7]. However, the factors resulting in sleep disturbance are not well understood.

In patients with moderate to severe COPD, nocturnal desaturation did not correlate with sleep quality or quality of life [8]. In another study, disturbed sleep was correlated with cough and dyspnea symptoms, but not with forced expiratory volume in the first second $\left(\mathrm{FEV}_{1}\right)$ in patients with COPD [7]. In addition, whether current pulmonary medications for COPD, including anticholinergics, theophylline, steroids, and beta2 agonists could improve or impair sleep quality is not well known [9-14]. This study was conducted, therefore, to identify the factors resulting in sleep disturbance in patients with COPD in Taiwan.

\section{Methods}

\section{Patients}

This study was conducted in accordance with the amended Declaration of Helsinki. The study was approved by the Institutional Review Boards of all the hospitals involved.

A retrospective, observational, multicenter research study was performed across six participating hospitals, including four medical centers and two regional hospitals, three in northern Taiwan, one in center-western Taiwan, two in southwestern Taiwan. Between December 2011 and November 2013, patients over 40 years of age with COPD, who were followed in an outpatient pulmonary clinic, were enrolled. Patients with a COPD diagnosis, based on the Global Initiatives for Chronic Obstructive Lung Disease (GOLD) guidelines, were included [15]. The GOLD guidelines are used worldwide in the diagnosis and management of COPD. COPD severity is staging by lung function only according to old GOLD guideline [16]. According to the 2007 GOLD definition: Stage 1: FEV $1 \geq 80 \%$ predicted; Stage: 2 FEV1 $<80 \%$ predicted and $\geq 50 \%$ predicted; Stage 3: FEV1 $<50 \%$ predicted and $\geq 30 \%$ predicted; and Stage 4 : FEV $1<30 \%$ predicted. In the GOLD guideline updated in 2011, COPD patients are classified into four groups by their symptoms and lung function [15]. COPD symptoms were evaluated by mMRC or CAT as follows: less symptoms patient (A or $\mathrm{C}$ ) : mMRC $0-1$ or CAT $<10$; More symptoms patients $(\mathrm{B}$ or $\mathrm{D}): \mathrm{mMRC} \geq 2$ or $\mathrm{CAT} \geq 10$. Low risk patients (A or B): FEV1\% predicted $\geq 50 \%$ or COPD exacerbation history $0-1$; High risk patients $(C$ or $D)$ : FEV1\% predicted $<50 \%$ or COPD exacerbation history $\geq 2$. The patients with COPD are categorized into $\mathrm{A}, \mathrm{B}, \mathrm{C}$, and D, four groups.

All participants had pulmonary function tests within one year and at least one COPD Assessment Test (CAT) [17], one Modified Medical Research Council (mMRC) dyspnea scale [18], and one Pittsburgh Sleep Quality Index (PSQI) [19]. Patients with a history of bronchial asthma or malignancy were excluded.

\section{Data collection}

Medical records were retrospectively reviewed and analyzed for the following data: age, sex, body mass index (BMI), smoking status, COPD medications prescribed at

Table 1 Demographic characteristics of the study population $(n=377)$

\begin{tabular}{|c|c|}
\hline Characteristics & Mean \pm SD \\
\hline Age, years & $73.0 \pm 10.1$ \\
\hline Male sex, n (\%) & $371(98.4 \%$ \\
\hline $\mathrm{BMI},\left(\mathrm{kg} / \mathrm{m}^{2}\right)$ & $23.6 \pm 3.0$ \\
\hline \multicolumn{2}{|l|}{ Smoking history } \\
\hline Never smoker, n (\%) & $22(6.0 \%)$ \\
\hline Ex-smoker, n (\%) & $232(63.0 \%$ \\
\hline Current smoker, n (\%) & $114(31 \%)$ \\
\hline $\mathrm{FEV}_{1}, \mathrm{~L}$ & $1.4 \pm 0.5$ \\
\hline $\mathrm{FEV}_{1}$, predicted $\%$ & $59.8 \pm 23.0$ \\
\hline Exacerbation in previous year, times & $0.6 \pm 1.2$ \\
\hline \multicolumn{2}{|l|}{ Comorbidities } \\
\hline Cardiovascular disease, n (\%) & $157(41.6 \%$ \\
\hline Ischemic heart disease, n (\%) & $35(9.3 \%)$ \\
\hline Heart failure, n (\%) & $15(4.0 \%)$ \\
\hline Hypertension, n (\%) & $129(34.2 \%$ \\
\hline Arrhythmia, n (\%) & $19(5.0 \%)$ \\
\hline Depression, n (\%) & $10(2.7 \%)$ \\
\hline \multicolumn{2}{|l|}{ Maintenance inhaler } \\
\hline LABA, n (\%) & $18(4.8 \%)$ \\
\hline LAMA, n (\%) & $87(23.1 \%)$ \\
\hline LABA/LAMA, n (\%) & $21(5.6 \%)$ \\
\hline LABA/ICS, n (\%) & $72(19.1 \%)$ \\
\hline LAMA/ICS, n (\%) & $3(0.8 \%)$ \\
\hline LABA/LAMA/ICS, n (\%) & $90(23.9 \%)$ \\
\hline No maintenance inhaler, n (\%) & $86(22.8 \%)$ \\
\hline \multicolumn{2}{|l|}{ GOLD classification } \\
\hline Group A, n (\%) & $60(15.9 \%)$ \\
\hline Group B, n (\%) & $150(39.8 \%$ \\
\hline Group C, n (\%) & $34(9.0 \%)$ \\
\hline Group D, n (\%) & $133(35.3 \%$ \\
\hline \multicolumn{2}{|l|}{ PSQI score } \\
\hline PSQI >5, n (\%) & $200(53.1 \%$ \\
\hline PSQI $\leqq 5, n(\%)$ & $177(46.9 \%$ \\
\hline
\end{tabular}

Abbreviations: $B M I$ body mass index, GOLD Global Initiative for Chronic Obstructive Lung Disease, $F E V_{1}$ forced expiratory volume in the first second, FVC forced vital capacity, ICS inhaled corticosteroids, LABA long-acting beta agonists, LAMA long-acting muscarinic antagonist, PSQI Pittsburgh sleep quality index 
outpatient clinics, clinical symptoms, presence of wheezing recorded in the medical charts, pulmonary function tests, and medical history of comorbidities. The COPD maintenance inhaler was defined as an inhaler continuously prescribed for 3 months.

\section{Measures}

The PSQI is a self-rating screening tool that measures quality of sleep. In addition to a total score, PSQI provides seven components of sleep including quality, latency, duration, efficiency, sleep disturbances, use of sleeping medication, and daytime dysfunction. Each component is scored from 0 to 3 , and seven component scores are then summed to gain a global score [19]. A PSQI global score $>5$ indicates poor sleep quality [19]. The traditional Chinese version of PSQI was used to assess sleep quality in this study [20]. The results of the PSQI questionnaire were retrospectively collected and analyzed. The CAT is a questionnaire for assessing the health status of COPD [17]. The test has eight items including cough, phlegm, chest tightness, breathlessness, activities, confidence, sleep, and energy. Each item can be scored as a single scale (from 0 to 5 ) with total scores ranging from 0 to 40. Higher CAT scores indicate poorer health. The modified Medical Research Council (mMRC) scale include five statements for rating dyspnea from 0 to 4, and higher mMRC grades indicate more dyspnea [18]. According to the GOLD guidelines, either a $m M R C \geq 2$ or a CAT score $\geq 10$ indicate more symptoms [15].

\section{Statistical analysis}

Patient demographics, clinical characteristics, and medication use were summarized using descriptive statistics and data were expressed as mean \pm standard deviation (SD). Comparisons between groups were made using the independent $t$-test, Chi-square test, one-way ANOVA, or Kruskal-Wallis one-way analysis of variance, where appropriate. Potential risk factors causing poor sleep quality in patients with COPD, including age, BMI, lung function, clinical symptoms, medications, medical history of comorbidities, and symptoms scores, were analyzed using univariate and multivariate analysis by applying a multiple logistic regression. All statistical analyses were performed using the using Statistical Analysis Software (SAS) version 9.3 (SAS Institute Inc., Cary, NC, USA).

\section{Results}

A total of 377 stable patients with COPD and who attended the outpatient clinic and fulfilled the study criteria were analyzed. Table 1 shows the patients' characteristics, including age, sex, $\mathrm{BMI}, \mathrm{FEV}_{1} \%$ predicted, $\mathrm{FVC} \%$ predicted, GOLD group, comorbidities, and current COPD medication. Most patients were elderly and $98 \%$ were male. According to the GOLD classification, most patients were classified into GOLD groups B and D. Among those classified, $53 \%$ had poor sleep quality (PSQI $>5$ ).

Patients with COPD were divided by their pulmonary function tests according to the 2007 GOLD classification [16]. Based on the 2007 GOLD classification system, the percentages of subjects with PSQI scores greater than 5 among the four groups was not significant (Table 2).

The COPD patients were also classified using the 2011 GOLD classification system [15], and the percentages of patients with PSQI $>5$ between the GOLD groups A, B, $\mathrm{C}$, and D were $43.3,54.0,38.2$, and $60.2 \%$, respectively $(p<0.05)$ (Table 3).

Table 4 demonstrated the specific components obtained from the PSQI. Among the seven components, sleep disturbance achieved the highest score compared with the other components. The most common sleep disturbances were "getting up to use the bathroom" (70.3\%), "wake up at night or early morning" (40.3\%) and "cough and snore loudly at night" (15.9\%). The percentage of the symptoms of sleep disturbance had no statistical difference between different stages of COPD according to the GOLD 2007 classification. (Table 5) We divided the subjects by the 2011 GOLD classification, patients had high percentage of "wake up at night or early morning" and "get up to use the bathroom" on GOLD group B and group D (Table 6).

Table 7 shows the results of univariate analysis of variables associated with poor sleep quality (PSQI $>5$ ) in patients with COPD based on logistic regression. Inhaled corticosteroids and the presence of a wheeze showed positive correlations with poor sleep quality scores with odds ratios (ORs) of 1.66 and 1.51, respectively. The CAT and MMRC scores also correlated with PSQI scores with ORs

Table 2 Measurements of COPD based on the 2007 GOLD classification

\begin{tabular}{|c|c|c|c|c|c|}
\hline & GOLD Stage 1 & GOLD Stage 2 & GOLD Stage 3 & GOLD Stage 4 & $P$-value \\
\hline & $N=68$ & $N=161$ & $N=123$ & $N=25$ & \\
\hline $\mathrm{MMRC}$, mean $\pm \mathrm{SD}$ & $1.50 \pm 0.76$ & $1.78 \pm 0.75$ & $1.96 \pm 0.95$ & $2.33 \pm 1.09$ & $<0.001$ \\
\hline $\mathrm{CAT}$, mean $\pm \mathrm{SD}$ & $9.15 \pm 6.91$ & $9.53 \pm 6.35$ & $11.07 \pm 7.11$ & $16.83 \pm 8.29$ & $<0.001$ \\
\hline $\mathrm{PSQ}$ score, mean $\pm \mathrm{SD}$ & $6.54 \pm 3.57$ & $6.43 \pm 3.50$ & $6.33 \pm 3.66$ & $6.44 \pm 3.16$ & 0.970 \\
\hline PSQI >5, n (\%) & $36(52.9)$ & $85(52.8)$ & $64(52.0)$ & $15(60.0)$ & 0.910 \\
\hline
\end{tabular}

Abbreviations: CAT COPD assessment test, GOLD Global Initiative for Chronic Obstructive Lung Disease, mMRC modified Medical Research Council, PSQI, Pittsburgh Sleep Quality Index 
Table 3 Measurements of COPD based on 2011 GOLD classification

\begin{tabular}{|c|c|c|c|c|c|}
\hline & GOLD group A & GOLD group B & GOLD group C & GOLD group D & $P$-value \\
\hline & $N=60$ & $N=150$ & $N=34$ & $N=133$ & \\
\hline $\mathrm{MMRC}$, mean $\pm \mathrm{SD}$ & $0.87 \pm 0.34$ & $2.05 \pm 0.58$ & $0.72 \pm 0.46$ & $2.31 \pm 0.81$ & $<0.001$ \\
\hline$C A T$, mean $\pm S D$ & $4.52 \pm 2.14$ & $11.09 \pm 6.75$ & $4.74 \pm 2.69$ & $13.84 \pm 7.08$ & $<0.001$ \\
\hline PSQI score, Mean \pm SD & $5.63 \pm 2.92$ & $6.67 \pm 3.68$ & $5.03 \pm 3.29$ & $6.85 \pm 3.57$ & 0.008 \\
\hline PSQI >5, n (\%) & 26 (43.3\%) & 81 (54.0\%) & 13 (38.2 \%) & 80 (60.2 \%) & 0.046 \\
\hline
\end{tabular}

Abbreviations: CAT COPD assessment test, GOLD Global Initiative for Chronic Obstructive Lung Disease, mMRC modified Medical Research Council, PSQ/ Pittsburgh Sleep Quality Index

of 1.09 (95\% confidence interval [CI], 1.05-1.13) and 1.30 (95\% CI, 1.02-1.66), respectively. Upon multivariate analysis, the CAT score remained an independent factor in poor sleep quality with an OR of 1.09 (95 \% CI, 1.04-1.14; $p<0.001$ ).

To explore the factors contributing to poor sleep quality using the CAT score, the differences in CAT items between good and poor sleepers were further analyzed. Among all participants, 131 patients had all detailed specific items on COPD assessment tests recorded. Not surprisingly, "sleep problem" was one factor in poor sleepers. However, in addition, higher phlegm production was a significant factor in poor sleepers (Table 8).

\section{Discussion}

Our study demonstrated that $53 \%$ of patients with COPD in our cohort had poor sleep quality (PSQI score $>5$ ). A high prevalence of poor sleep quality in patients with COPD has been reported in previous studies $[1,2,8]$. In a recent real-world study, $78 \%$ of patients with COPD reported night time disturbances as measured by the Jenkins Sleep Questionnaire [21]. In a telephone study, Ohayon reported COPD subjects had higher insomnia symptoms than non-COPD subjects (48.1 versus $27.6 \%$ respectively) [22].

Our study also confirmed sleep disturbances, as well as cough and dyspnea, as major concerns in patients with COPD. Some researchers suggest that poor sleep quality might result in cognitive dysfunction, depression, anxiety, poor survival and poor quality of life [7].

Table 4 Sleep component scores based on the PSQI in patients with COPD

\begin{tabular}{ll}
\hline Components & Mean \pm SD \\
\hline Sleep quality & $0.97 \pm 0.75$ \\
Sleep latency & $1.16 \pm 1.09$ \\
Sleep duration & $1.11 \pm 0.94$ \\
Sleep efficiency & $0.73 \pm 1.04$ \\
Sleep disturbance & $1.50 \pm 0.59$ \\
Use of sleeping medication & $0.47 \pm 1.03$ \\
Daytime dysfunction & $0.48 \pm 0.66$ \\
\hline
\end{tabular}

Abbreviation: PSQI Pittsburgh Sleep Quality Index
Determining which factors are associated with sleep disturbances in patients with COPD may improve their treatment strategy.

A high prevalence of sleep symptoms among patients with COPD was discovered approximately thirty years ago [23] but poor sleep quality remained a forgotten dimension of COPD until recently [24]. Few studies, however, have addressed factors such as medical history, pulmonary function tests, COPD medication, and questionnaires when analyzing sleep disturbances in COPD patients.

In this study, poor sleep quality was defined according to PSQI scores and included several symptoms. Interestingly, the most common symptoms that disturbed sleep in our COPD cohort were "getting up to use the bathroom" (69.9\%) and "wake up at night or early morning" (40.3\%) whereas "cough and snore loudly at night" or "bad dream" comprised the third and fourth complaints (15.9 and $11.9 \%$, respectively). Breathlessness, cough, sputum production, and wheezing were also among the most common symptoms in patients with COPD. In our study, we found the GOLD guideline updated in 2011, which was classified by their symptoms as well as lung function were related to sleep disturbance as shown in Tables 2, 3, 5, and 6. More symptoms patients (group B or group D; mMRC $\geq 2$ or $\mathrm{CAT} \geq 10$ ) had a higher percentage of sleep disturbance including wake up at night or early morning, get up to use the bathroom, bad dream and cannot breathe comfortably.

In a nation-wide longitudinal population study, the overall prevalence of nocturnal voiding was $56 \%$ at 50 years of age increasing to $74 \% 10$ years later [25]. The average age of our cohort was 73 years of age with $69.9 \%$ complaining of nocturnal voiding symptoms, similar to the results from the population study. An epidemiological study of nocturia by Yoshimura et al. suggested that, besides benign prostate hypertrophy, nocturia correlated with age, race, medical problems (such as hypertension, diabetes, and stroke) psychological problems, quality of life and mortality [26]. Stephenson et al. reported that use of inhaled anticholinergic medications was associated with an increased risk of acute urinary retention in men with COPD, especially in those patients with benign prostate hyperplasia [27]. However, another study concluded that 
Table 5 The distribution of sleep disturbances among patients with COPD based on 2007 GOLD classification

\begin{tabular}{|c|c|c|c|c|c|}
\hline \multirow[t]{2}{*}{ Items reporting $\geq 3$ times per week } & GOLD Stage 1 & GOLD Stage2 & GOLD Stage 3 & GOLD Stage 4 & \multirow[t]{2}{*}{$P$-value } \\
\hline & N (\%) & N (\%) & N (\%) & N (\%) & \\
\hline Wake up at night or early morning & $29(42.6 \%)$ & $66(41.0 \%)$ & $43(35.0 \%)$ & $14(56.0 \%)$ & 0.240 \\
\hline Get up to use the bathroom & $45(66.2 \%)$ & $118(73.3 \%)$ & $80(65.0 \%)$ & $22(88.0 \%)$ & 0.085 \\
\hline Cannot breathe comfortably & $2(2.9 \%)$ & $11(6.8 \%)$ & $11(8.9 \%)$ & $4(16.0 \%)$ & 0.161 \\
\hline Cough or snore loudly & $10(14.7 \%)$ & $23(14.3 \%)$ & $21(17.1 \%)$ & $6(24.0 \%)$ & 0.628 \\
\hline Feel too cold & $0(0.0 \%)$ & $4(2.5 \%)$ & $2(1.6 \%)$ & 0 (0.0 \%) & 0.508 \\
\hline Feel too hot & $0(0.0 \%)$ & $4(2.5 \%)$ & $2(1.6 \%)$ & 1 (4.0\%) & 0.512 \\
\hline Bad dreams & $9(13.2 \%)$ & $21(13.0 \%)$ & $13(10.6 \%)$ & 2 (8.0 \%) & 0.829 \\
\hline Pain & $3(4.4 \%)$ & $8(5.0 \%)$ & $7(5.7 \%)$ & $2(8.0 \%)$ & 0.910 \\
\hline
\end{tabular}

tiotropium did not affect lower urinary tract function in patients with COPD [28]. In our study, the use of inhaled long-acting muscarinic antagonists was not associated with poor sleep quality in the COPD patients. In patients with heart failure, nocturia is common and associated with sleep disturbance [29]. Heart failure may be one of the factors contributing to sleep disturbance in the patients with COPD. Although the most common cause of sleep disturbance was getting up to use the bathroom, patients with poor sleep quality also had more complaints of "wake up at night or early morning", "cough or snore loudly", and "cannot breathe comfortably" compared with those patients without poor sleep quality. Thus, the current study offers physicians significant information regarding ways to discover and solve sleep problems in patients with COPD. In a national epidemiology survey in Taiwan [30], males were predominated, especially in current and former smokers from 91 to $84 \%$. Our result had similar male predominant population which may due to our patients are mostly current or formal smokers.

Multivariate analysis showed that high CAT scores predicted poor sleep quality. These results implied that surveying the causes of sleep disturbance was important for patients with CAT scores $>10$. Mehta et. al also reported that COPD patients with high CAT scores had a higher frequency of insomnia than those with low CAT scores [31]. A previous study reported an increased prevalence of night symptoms as the severity of airflow limitation increased [32]. In contrast, another study found that $\mathrm{FEV}_{1}$ was not associated with disturbed sleep nor with health related quality of life [7,33]. In our study, we found no relationship between pulmonary function tests and poor sleep quality. This result implies that poor sleep quality is not directly related to pulmonary function tests. However, other underlying diseases, medical comorbidities, and adverse effects of drug therapy may be associated factors.

The causes of sleep disturbance in patients with COPD are multifactorial, includes respiratory symptoms [34], obstructive sleep apnea (OSA), psychiatric disorders, and medication-related insomnia [9, 35]. Sleep disturbances due to COPD medications is a common problem, and oral steroids, inhaled steroids, beta agonists, and theophylline have been implicated [10, 36-38]. In our studies, the presence of wheeze, inhaled ICS, and significant phlegm production contributed to poor sleep quality. After multivariate analysis, however, no single medication caused poor sleep quality; only the CAT score predicted poor sleep quality in our COPD population. "Much phlegm" on the CAT questionnaire in our cohort was significant in poor sleepers. The CAT score is a simple questionnaire developed to assess and monitor the

Table 6 The distribution of sleep disturbances among patients with COPD based on 2011 GOLD classification

\begin{tabular}{|c|c|c|c|c|c|}
\hline \multirow[t]{2}{*}{ Items reporting $\geq 3$ times per week } & GOLD group A & GOLD group B & GOLD group C & GOLD group D & \multirow[t]{2}{*}{$P$-value } \\
\hline & N (\%) & N (\%) & N (\%) & N (\%) & \\
\hline Wake up at night or early morning & $15(25.0 \%)$ & 70 (46.7 \%) & $10(29.4 \%)$ & $57(42.9 \%)$ & 0.015 \\
\hline Get up to use the bathroom & $37(61.7 \%)$ & $114(76.0 \%)$ & 19 (55.9\%) & $95(71.4 \%)$ & 0.047 \\
\hline Cannot breathe comfortably & $0(0.0 \%)$ & $11(7.3 \%)$ & $2(5.9 \%)$ & $15(11.3 \%)$ & 0.050 \\
\hline Cough or snore loudly & $8(13.3 \%)$ & $21(14.0 \%)$ & $4(11.8 \%)$ & $27(20.3 \%)$ & 0.383 \\
\hline Feel too cold & $0(0.0 \%)$ & $4(2.7 \%)$ & $0(0.0 \%)$ & $2(1.5 \%)$ & 0.452 \\
\hline Feel too hot & $0(0.0 \%)$ & $4(2.7 \%)$ & $0(0.0 \%)$ & $3(2.3 \%)$ & 0.487 \\
\hline Bad dreams & $4(6.7 \%)$ & $26(17.3 \%)$ & $1(2.9 \%)$ & $14(10.5 \%)$ & 0.035 \\
\hline Pain & $1(1.7 \%)$ & $9(6.0 \%)$ & $2(5.9 \%)$ & $8(6.0 \%)$ & 0.597 \\
\hline
\end{tabular}


Table 7 Variables associated with poor sleep quality among patients with COPD

\begin{tabular}{|c|c|c|c|c|}
\hline Characteristics & Parameter estimate & Standard error & Odds ratio $(95 \% \mathrm{Cl})$ & $P$-value \\
\hline \multicolumn{5}{|l|}{ Univariate analysis } \\
\hline Age & 0.006 & 0.010 & $1.01(0.99,1.03)$ & 0.563 \\
\hline BMI & 0.027 & 0.026 & $1.03(0.98,1.08)$ & 0.311 \\
\hline $\mathrm{FEV}_{1}$, predicted $\%$ & -0.003 & 0.004 & $1.00(0.99,1.01)$ & 0.555 \\
\hline Wheezing* & 0.509 & 0.228 & $1.66(1.06,2.60)$ & 0.026 \\
\hline Theophylline & 0.134 & 0.515 & $1.14(0.42,3.14)$ & 0.794 \\
\hline Oral steroids & -0.281 & 0.218 & $0.76(0.49,1.16)$ & 0.197 \\
\hline Inhaled LABA & -0.363 & 0.486 & $0.70(0.27,1.80)$ & 0.455 \\
\hline Inhaled LAMA & -0.369 & 0.245 & $0.69(0.43,1.12)$ & 0.133 \\
\hline Inhaled ICS* & 0.412 & 0.210 & $1.51(1.00,2.28)$ & 0.049 \\
\hline Ischemic heart disease & 0.312 & 0.362 & $1.37(0.67,2.77)$ & 0.389 \\
\hline Heart failure & -0.549 & 0.537 & $0.58(0.20,1.66)$ & 0.307 \\
\hline Hypertension & 0.409 & 0.220 & $1.50(0.98,2.32)$ & 0.063 \\
\hline Arrhythmia & 0.438 & 0.487 & $1.55(0.60,4.03)$ & 0.368 \\
\hline Depression & 1.294 & 0.797 & $3.65(0.76,17.4)$ & 0.105 \\
\hline Anxiety & -0.124 & 0.823 & $0.88(0.18,4.43)$ & 0.880 \\
\hline CAT score* & 0.085 & 0.017 & $1.09(1.05,1.13)$ & $<0.001$ \\
\hline mMRC score* & 0.264 & 0.125 & $1.30(1.02,1.66)$ & 0.035 \\
\hline
\end{tabular}

Abbreviations: $B M I$ body mass index, $F E V_{1}$ forced expiratory volume in the first second, ICS inhaled corticosteroids, LABA long-acting beta agonist, LAMA long-acting muscarinic antagonist, CAT COPD assessment test, $m M R C$ modified Medical Research Council, $C l$ confidence interval

${ }^{*} p<0.05$

symptoms of COPD [17]. We recommend the use of the CAT questionnaire rather than the MMRC to monitor symptoms of COPD because sleep disturbance is a major complaint in patients with COPD.

Our study had several limitations. We did not perform polysomnography to rule out sleep disorders such as OSA. Although OSA is prevalent in some selected COPD patients, the prevalence rate of OSA in patients with COPD was similar to the general population in the other reports [24, 39]. In addition, not all the factors which disturbed sleep (such as depression) were collected. The subjects included in our study may have had more medical comorbidities (and the percentage of GOLD B and D patients may have been higher) than those found in the general COPD population. Finally, the study was retrospective and the most data were collected in older men with COPD.

\section{Conclusions}

More than half of our patients with COPD experienced poor sleep quality. The most common sleep complaints included getting up for the bathroom, waking up at

Table 8 Specific items on COPD Assessment Test between patients with COPD with poor sleep quality (PSQI > 5) and those without poor sleep quality

\begin{tabular}{lccc}
\hline & With poor sleep quality $(N=86)$ & Without poor sleep quality $(N=45)$ & $P$-value \\
\hline Cough & $2.0 \pm 1.7$ & $1.6 \pm 1,3$ & 0.123 \\
Phlegm* & $2.4 \pm 1.6$ & $1.8 \pm 1.5$ & 0.030 \\
Chest tightness & $1.4 \pm 1.4$ & $1.1 \pm 1.5$ & 0.286 \\
Breathlessness & $2.4 \pm 1.7$ & $2.2 \pm 1.9$ & 0.558 \\
Activities & $1.0 \pm 1.4$ & $1.0 \pm 1.6$ & 0.805 \\
Confidence & $1.1 \pm 1.5$ & $1.1 \pm 1.7$ & 0.953 \\
Sleep* & $2.1 \pm 1.9$ & $0.7 \pm 1.4$ & $<0.001$ \\
Energy & $1.8 \pm 1.6$ & $1.4 \pm 1.7$ & 0.176 \\
CAT score* & $14.4 \pm 8.1$ & $11.0 \pm 7.9$ & 0.022 \\
\hline
\end{tabular}

${ }^{*} p<0.05$ 
night or in the early morning, and coughing or snoring loudly. Symptoms including wheezing, phlegm, and the use of inhaled corticosteroid may also have contributed to poor sleep quality in these COPD patients.

\section{Abbreviations}

BMI, body mass index; CAT, COPD Assessment Test; COPD, chronic obstructive lung disease; FEV1, forced expiratory volume in the first second FVC, forced vital capacity; GOLD, Global Initiatives for Chronic Obstructive Lung Disease; ICS, inhaled corticosteroids; LABA, long-acting beta agonists; LAMA, long-acting muscarinic antagonist; mMRC, Modified Medical Research Council; PSQI, Pittsburgh Sleep Quality Index; REM, rapid eye movement

\section{Acknowledgments}

The TOLD study received financial support from Novartis Pharmaceuticals Corporation. Data management and statistical analysis were supported by the CRO service division of Formosa Biomedical Technology Corp.

\section{Availability of data and materials}

These clinical data will not be shared because of confidentiality.

\section{Authors' contributions}

NHC, YHT, YFW, SLC, JYH, PHK, and CJY conceived the study and participated in its design and coordination. SWL and CSL participated in the data analysis and interpretation. CHC, LPC, and NHC drafted the manuscript. All authors read and approved the final manuscript.

\section{Competing interests}

The authors declare that they have no competing interests.

\section{Ethics approval and consent to participate}

The Chang Gung Memorial Hospital Institutional Review Board and Ethics Committees approved this study (approval number: 101-4232B) and waived the need for written informed consent. All individual information was delinked.

\section{Author details \\ 'Department of Pulmonary and Critical Care Medicine, Linkou Chang-Gung Memorial Hospital, Chang-Gung medical foundation, Taoyuan, Taiwan. ${ }^{2}$ Chang-Gung University College of Medicine, Taoyuan, Taiwan. ${ }^{3}$ Department of Pulmonary and Critical Care Medicine, Chiayi Chang-Gung Memorial Hospital, Chang-Gung medical foundation, Chiayi, Taiwan. ${ }^{4}$ Department of Internal Medicine, E-Da Hospital/I-Shou University, Kaohsiung, Taiwan. ${ }^{5}$ Department of Internal Medicine, Division of Thoracic Medicine, Far Eastern Memorial Hospital, New Taipei City, Taiwan. ${ }^{6}$ Department of Chemical Engineering and Materials Science, Yuan-Ze University, Taoyuan City, Taiwan. ${ }^{7}$ Division of Chest Medicine, Taichung Veterans General Hospital, Taichung, Taiwan. ${ }^{8}$ Department of Internal Medicine, National Taiwan University Hospital, Taipei, Taiwan.}

Received: 20 April 2016 Accepted: 4 August 2016 Published online: 08 August 2016

\section{References}

1. Nunes DM, Mota RM, de Pontes Neto OL, Pereira ED, de Bruin VM, de Bruin PF. Impaired sleep reduces quality of life in chronic obstructive pulmonary disease. Lung. 2009;187(3):159-63.

2. Scharf SM, Maimon N, Simon-Tuval T, Bernhard-Scharf BJ, Reuveni $H_{\text {, }}$ Tarasiuk A. Sleep quality predicts quality of life in chronic obstructive pulmonary disease. Int J Chron Obstruct Pulmon Dis. 2011;6:1-12.

3. Valipour A, Lavie P, Lothaller H, Mikulic I, Burghuber OC. Sleep profile and symptoms of sleep disorders in patients with stable mild to moderate chronic obstructive pulmonary disease. Sleep Med. 2011;12(4):367-72.

4. Fleetham J, West P, Mezon B, Conway W, Roth T, Kryger M. Sleep, arousals, and oxygen desaturation in chronic obstructive pulmonary disease. The effect of oxygen therapy. Am Rev Respir Dis. 1982;126(3):429-33.

5. Mulloy E, McNicholas WT. Ventilation and gas exchange during sleep and exercise in severe COPD. Chest. 1996;109(2):387-94.

6. Ballard RD, Clover CW, Suh BY. Influence of sleep on respiratory function in emphysema. Am J Respir Crit Care Med. 1995;151(4):945-51.
7. Omachi TA, Blanc PD, Claman DM, Chen H, Yelin EH, Julian L, Katz PP. Disturbed sleep among COPD patients is longitudinally associated with mortality and adverse COPD outcomes. Sleep Med. 2012;13(5):476-83.

8. Lewis CA, Fergusson W, Eaton T, Zeng I, Kolbe J. Isolated nocturnal desaturation in COPD: prevalence and impact on quality of life and sleep. Thorax. 2009:64(2):133-8.

9. McNicholas WT, Calverley PM, Lee A, Edwards JC. Long-acting inhaled anticholinergic therapy improves sleeping oxygen saturation in COPD. Eur Respir J. 2004;23(6):825-31.

10. Roehrs T, Merlotti L, Halpin D, Rosenthal L, Roth T. Effects of theophylline on nocturnal sleep and daytime sleepiness/alertness. Chest. 1995;108(2):382-7.

11. Mastronarde JG, Wise RA, Shade DM, Olopade CO, Scharf SM. Sleep quality in asthma: results of a large prospective clinical trial. J Asthma. 2008:45(3): 183-9.

12. Chrousos GA, Kattah JC, Beck RW, Cleary PA. Side effects of glucocorticoid treatment. Experience of the Optic Neuritis Treatment Trial. JAMA. 1993; 269(16):2110-2.

13. Calverley PM, Anderson JA, Celli B, Ferguson GT, Jenkins C, Jones PW, Yates JC, Vestbo J. Salmeterol and fluticasone propionate and survival in chronic obstructive pulmonary disease. N Engl J Med. 2007;356(8):775-89.

14. Fitzpatrick MF, Mackay T, Driver H, Douglas NJ. Salmeterol in nocturnal asthma: a double blind, placebo controlled trial of a long acting inhaled beta 2 agonist. BMJ. 1990;301(6765):1365-8.

15. Vestbo J, Hurd SS, Agusti AG, Jones PW, Vogelmeier C, Anzueto A, Barnes PJ, Fabbri LM, Martinez FJ, Nishimura M, et al. Global strategy for the diagnosis, management, and prevention of chronic obstructive pulmonary disease: GOLD executive summary. Am J Respir Crit Care Med. 2013;187(4):347-65.

16. Rabe KF, Hurd S, Anzueto A, Barnes PJ, Buist SA, Calverley P, Fukuchi Y, Jenkins C, Rodriguez-Roisin $R$, van Weel $C$, et al. Global strategy for the diagnosis, management, and prevention of chronic obstructive pulmonary disease: GOLD executive summary. Am J Respir Crit Care Med. 2007;176(6):532-55.

17. Jones PW, Harding G, Berry P, Wiklund I, Chen WH, Kline Leidy N. Development and first validation of the COPD Assessment Test. Eur Respir J. 2009;34(3):648-54.

18. Mahler DA, Wells CK. Evaluation of clinical methods for rating dyspnea. Chest. 1988;93(3):580-6.

19. Buysse DJ, Reynolds 3rd CF, Monk TH, Berman SR, Kupfer DJ. The Pittsburgh Sleep Quality Index: a new instrument for psychiatric practice and research. Psychiatry Res. 1989;28(2):193-213.

20. Tsai PS, Wang SY, Wang MY, Su CT, Yang TT, Huang CJ, Fang SC. Psychometric evaluation of the Chinese version of the Pittsburgh Sleep Quality Index (CPSQI) in primary insomnia and control subjects. Qual Life Res. 2005;14(8):1943-52.

21. Price $D$, Small M, Milligan G, Higgins V, Gil EG, Estruch J. Impact of nighttime symptoms in COPD: a real-world study in five European countries. Int J Chron Obstruct Pulmon Dis. 2013;8:595-603.

22. Ohayon MM. Chronic obstructive pulmonary disease and its association with sleep and mental disorders in the general population. J Psychiatr Res. 2014:54:79-84.

23. Klink M, Quan SF. Prevalence of reported sleep disturbances in a general adult population and their relationship to obstructive airways diseases. Chest. 1987;91(4):540-6.

24. McNicholas WT, Verbraecken J, Marin JM. Sleep disorders in COPD: the forgotten dimension. Eur Respir Rev. 2013;22(129):365-75.

25. Hakkinen JT, Hakama M, Shiri R, Auvinen A, Tammela TL, Koskimaki J. Incidence of nocturia in 50 to 80-year-old Finnish men. J Urol. 2006;176(6 Pt 1):2541-5. discussion 2545

26. Yoshimura K. Correlates for nocturia: a review of epidemiological studies. Int J Urol. 2012:19(4):317-29.

27. Stephenson A, Seitz D, Bell CM, Gruneir A, Gershon AS, Austin PC, Fu L, Anderson GM, Rochon PA, Gill SS. Inhaled anticholinergic drug therapy and the risk of acute urinary retention in chronic obstructive pulmonary disease: a population-based study. Arch Intern Med. 2011;171(10):914-20.

28. Miyazaki H, Suda T, Otsuka A, Nagata M, Ozono S, Hashimoto D, Nakamura Y, Inui N, Nakamura H, Chida K. Tiotropium does not affect lower urinary tract functions in COPD patients with benign prostatic hyperplasia. Pulm Pharmacol Ther. 2008;21(6):879-83.

29. Redeker NS, Adams L, Berkowitz R, Blank L, Freudenberger R, Gilbert M, Walsleben J, Zucker MJ, Rapoport D. Nocturia, sleep and daytime function in stable heart failure. J Card Fail. 2012;18(7):569-75.

30. Cheng SL, Chan MC, Wang CC, Lin CH, Wang HC, Hsu JY, Hang LW, Chang CJ, Perng DW, Yu CJ. COPD in Taiwan: a National Epidemiology Survey. Int J Chron Obstruct Pulmon Dis. 2015;10:2459-67. 
31. Mehta JR, Ratnani IJ, Dave JD, Panchal BN, Patel AK, Vala AU. Association of psychiatric co-morbidities and quality of life with severity of chronic obstructive pulmonary disease. East Asian Arch Psychiatry. 2014;24(4):148-55.

32. Agusti A, Hedner J, Marin JM, Barbe F, Cazzola M, Rennard S. Night-time symptoms: a forgotten dimension of COPD. Eur Respir Rev. 2011;20(121): 183-94.

33. Pickard AS, Yang Y, Lee TA. Comparison of health-related quality of life measures in chronic obstructive pulmonary disease. Health Qual Life Outcomes. 2011;9:26

34. Klink ME, Dodge R, Quan SF. The relation of sleep complaints to respiratory symptoms in a general population. Chest. 1994;105(1):151-4.

35. Martin RJ, Bartelson BL, Smith P, Hudgel DW, Lewis D, Pohl G, Koker P, Souhrada JF. Effect of ipratropium bromide treatment on oxygen saturation and sleep quality in COPD. Chest. 1999;115(5):1338-45.

36. Moser NJ, Phillips BA, Guthrie G, Barnett G. Effects of dexamethasone on sleep. Pharmacol Toxicol. 1996;79(2):100-2.

37. Kraft M, Wenzel SE, Bettinger CM, Martin RJ. The effect of salmeterol on nocturnal symptoms, airway function, and inflammation in asthma. Chest. 1997;111(5):1249-54

38. Barnes PJ. Inhaled glucocorticoids for asthma. N Engl J Med. 1995;332(13): 868-75.

39. Sanders MH, Newman AB, Haggerty CL, Redline S, Lebowitz M, Samet J, O'Connor GT, Punjabi NM, Shahar E. Sleep and sleep-disordered breathing in adults with predominantly mild obstructive airway disease. Am J Respir Crit Care Med. 2003;167(1):7-14.

\section{Submit your next manuscript to BioMed Central and we will help you at every step:}

- We accept pre-submission inquiries

- Our selector tool helps you to find the most relevant journal

- We provide round the clock customer support

- Convenient online submission

- Thorough peer review

- Inclusion in PubMed and all major indexing services

- Maximum visibility for your research

Submit your manuscript at www.biomedcentral.com/submit 